\title{
SIZE EFFECT ON SHEAR BEHAVIOR OF HIGH STRENGTH RC SLENDER BEAMS
}

\author{
Arun $\mathbf{M}^{\mathbf{1}}$, Ramakrishnan $\mathrm{S}^{\mathbf{2}}$ \\ ${ }^{1}$ Assistant Professor - Senior Grade, Department of Civil Engineering, Bannari Amman Institute of Technology, \\ Sathyamangalam, Tamilnadu, India - 638401 \\ ${ }^{2}$ Assistant Professor - Senior Grade, Department of Civil Engineering, Bannari Amman Institute of Technology, \\ Sathyamangalam, Tamilnadu, India - 638401
}

\begin{abstract}
Nine high strength reinforced concrete beams with minimum shear reinforcement and heavier than minimum as per ACI code, were tested to investigate their size effects on shear strength for medium depth beams (d ranges from 305 to $560 \mathrm{~mm}$ ), ultimate shear capacity and failure modes. Test variables were shear reinforcement percentage ( $\rho_{v}$ varying from 0.2682 to 0.3351 ), longitudinal steel percentage ( $\rho_{l}$ varying from 2.78 to 3.43) and effective depth (varying from 400 to $500 \mathrm{~mm}$ ) with constant compressive strength $\left(f_{c k}=70 \mathrm{MPa}\right)$ and shear span to effective depth $\left(a_{\sqrt{v}} / d\right)=2.6$. This study investigated the influence of beam depth with varying longitudinal reinforcement and minimum shear reinforcement. Test results were compared with the strengths predicted by ACI code, CEB-FIP Model, Zsutty's equation, Okumaro's equation and also with Bazant's method. ACI code and Okumaro's equation can predict the shear strength trend reasonably well for slender beams. The Bazant's method is underestimating the ultimate strength. The accuracy of the Zsutty's equation is relatively better than ACI approaches and but it does not take in to account the size effect. Canadian code provisions correlates well with the experimental results taking in to account the size effect.
\end{abstract}

Keywords: Size Effect, High strength concrete, Shear strength, Slender Beams, Varying Section Depth.

\section{INTRODUCTION}

The problem of shear failure of reinforced concrete beams has received much attention in technical literature due to its complex mechanism. A large number of experimental programme has been conducted all over the world using concrete with compressive strength lower than $40 \mathrm{MPa}$, most of these test specimens are usually smaller than in actual structural members, because it is practically difficult and expensive to carry out laboratory tests on large size specimens. Many current design methods are based on more or less statistic analysis of existing test results.

The diagonal shear failure of reinforced concrete beams has been known to be a brittle type of failure and it is already known that size effect occurs in both short and slender beams with normal strength concrete. Size effect is represented by a reduction in ultimate shear strength due to increase in beam size. In recent years with rapidly increasing use of high strength concrete, this issue becomes more important. High strength concrete is known to be more brittle than normal strength concrete. This will result in strong size effect in high strength concrete beams. However, the experimental information on this subject is limited. The experimental program described in this investigation attempts to provide more data on shear behavior of high strength concrete beams affected by size. The result should be useful for evaluating design methods used for high strength concrete beams.
ACI 318-05 equation (11-3), $\mathrm{V}_{\mathrm{c}}=0.16 \sqrt{f_{c^{\prime}}} \mathrm{b}_{\mathrm{w}} \mathrm{d}$ currently specifies the shear strength of reinforced concrete members where fc' is cylinder compressive strength of concrete in $\mathrm{MPa}$, d- effective depth of beams in $\mathrm{mm}$ and bw- breadth of beam in $\mathrm{mm}$. This code formula gives size independent concrete shear strength. From the literature study the following important points were observed. Diagonal tension failure was most common failure mode of the beam with shear span to effective depth $\left(a_{v} / d\right)>2.5$. It was observed that the ultimate shear strength reduced for beams with minimum shear reinforcement showing significant size effect. There is a more pronounced size effect in medium effective depth beams than in small depth beams $(\mathrm{d}<$ $305 \mathrm{~mm})$.

\section{EXPERIMENTAL PROGRAM}

This program consists of nine rectangular beams with constant width equal to $150 \mathrm{~mm}$ and overall depth varying from 400 to $500 \mathrm{~mm}$. In this study, three groups of concrete slender beams are consisting of three specimens with shear span to effective depth $\left(a_{v} / d\right)$ ratio equal to 2.6. The beams were tested to shear failure under two point symmetric top loads. The beams are designed to fail in shear before their flexure capacity is reached. The beams are longitudinally reinforced with $\rho_{1}$ varying from 2.78 to 3.43 and each beam is provided with minimum shear reinforcement as per ACI code $318-02$ 


$$
\rho_{\mathrm{v}(\min )}=\frac{A_{s v}}{b_{w} \cdot s_{v}} \text { where } \mathrm{s}_{\mathrm{v}}=0.065 \sqrt{f_{c^{\prime}}} / f_{y} \geq 0.33 / f_{y} \mathrm{MPa}
$$

Where fc' up to $120 \mathrm{MPa}$, nominal stirrup capacity $\mathrm{f}_{\mathrm{y}}$ not greater than $0.345 \mathrm{MPa}$ and maximum spacing of stirrups $0.5 \mathrm{~d}$. Here the study is made for medium range effective depth beam that is ( 305 to $560 \mathrm{~mm}$ ). The effective depth (d) chosen was from 400 to $500 \mathrm{~mm}$.

\subsection{Details of Test Specimen}

The details of each group specimen with respect to $\rho_{l}$ and $\rho_{v}$ are given in Table-1.

Table-1: Details of test specimen

\begin{tabular}{|l|l|l|l|l|l|l|}
\hline Specimen & $\begin{array}{l}\text { Effective } \\
\text { Depth (d) } \\
\text { in mm }\end{array}$ & $\begin{array}{l}\mathrm{S}_{\mathrm{v}}, \text { limit } \\
=0.5 \mathrm{~d} \\
\text { in mm }\end{array}$ & $\begin{array}{l}\rho_{\mathrm{v}}=100(\mathrm{~A} \\
\left.\text { sv } / \mathrm{b} \mathrm{S}_{\mathrm{v}}\right)\end{array}$ & $\begin{array}{l}\rho_{\mathrm{l}}=100( \\
\left.\mathrm{A}_{\mathrm{st}} / \mathrm{bd}\right)\end{array}$ & $\begin{array}{l}\text { Ast, } \\
\text { fy=415 }\end{array}$ & $\begin{array}{l}\text { Asv } \\
\text { fy=415 }\end{array}$ \\
\hline MNR1 & 400 & 200 & 0.3351 & 2.78 & $3 \# 25 \phi+1 \# 16 \phi$ & $2 \# 8 \phi$ \\
\hline MNR2 & 450 & 225 & 0.2978 & 2.78 & $3 \# 25 \phi+2 \# 16 \phi$ & $2 \# 8 \phi$ \\
\hline MNR3 & 500 & 250 & 0.2682 & 2.78 & $3 \# 25 \phi+2 \# 16 \phi$ & 2\#8 $\phi$ \\
\hline NNR1 & 400 & 200 & 0.3351 & 3.43 & $4 \# 25 \phi$ & 2\#8 $\phi$ \\
\hline NNR2 & 450 & 225 & 0.2978 & 3.43 & $4 \# 25 \phi+1 \# 16 \phi$ & 2\#8 $\phi$ \\
\hline NNR3 & 500 & 250 & 0.2682 & 3.43 & $4 \# 25 \phi+2 \# 16 \phi$ & 2\#8 $\phi$ \\
\hline ONR1 & 400 & 180 & 0.37 & 2.78 & $3 \# 25 \phi+1 \# 16 \phi$ & $2 \# 8 \phi$ \\
\hline ONR2 & 450 & 200 & 0.3351 & 2.78 & $3 \# 25 \phi+2 \# 16 \phi$ & 2\#8 $\phi$ \\
\hline ONR2 & 500 & 225 & 0.2978 & 2.78 & $4 \# 25 \phi$ & $2 \# 8 \phi$ \\
\hline
\end{tabular}

\section{RESULTS AND DISCUSSION}

The specimen remains elastic until flexure crack takes place. Diagonal crack occurs after the flexure crack obtained and widened quickly under increase in load as the diagonal crack width widens quickly a few of them merge and develop in to diagonal cracks that finally leads to the failure of beams. The inclined web shear crack may formed between the end support and loading point. The failure crack patterns of three groups of beams are similar. All beams failed in diagonal tension mode of shear failure. For the entire tested beam, primary shear crack angle varied between 30 to 40 degrees regardless of size and stirrup spacing. The mode of failure is given in Table- 2 along with the test results.

Table-2: Results of tested beams

\begin{tabular}{|l|l|l|l|l|l|l|l|l|}
\hline Specimen & $\begin{array}{l}\text { Effective } \\
\text { Depth (d) } \\
\text { in mm }\end{array}$ & $\begin{array}{l}\text { Breadth } \\
\text { of beam } \\
\text { in mm }\end{array}$ & $\mathrm{a}_{\mathrm{v}} / \mathrm{d}$ & $\begin{array}{l}\mathrm{f}_{\mathrm{ck}} \text { in } \\
\mathrm{MPa}\end{array}$ & $\mathrm{f}_{\mathrm{c}^{\prime}}$ & $\mathrm{V}_{\mathrm{cr}}(\mathrm{KN})$ & $\mathrm{V}_{\mathrm{u}}(\mathrm{KN})$ & Mode of Failure \\
\hline MNR1 & 400 & 150 & 2.6 & 61 & 48.8 & 145 & 268.69 & Diagonal Tension \\
\hline MNR2 & 450 & 150 & 2.6 & 61 & 48.8 & 140 & 254.845 & Diagonal Tension \\
\hline MNR3 & 500 & 150 & 2.6 & 61 & 48.8 & 110 & 193.43 & Diagonal Tension \\
\hline NNR1 & 400 & 150 & 2.6 & 47 & 37.6 & 120 & 264.52 & Diagonal Tension \\
\hline NNR2 & 450 & 150 & 2.6 & 47 & 37.6 & 100 & 233.53 & Diagonal Tension \\
\hline NNR3 & 500 & 150 & 2.6 & 61 & 48.8 & 90 & 193.03 & Diagonal Tension \\
\hline ONR1 & 400 & 150 & 2.6 & 47 & 37.6 & 145 & 268.69 & Diagonal Tension \\
\hline ONR2 & 450 & 150 & 2.6 & 47 & 37.6 & 100 & 250.223 & Diagonal Tension \\
\hline ONR3 & 500 & 150 & 2.6 & 47 & 37.6 & 80 & 207.61 & Diagonal Tension \\
\hline
\end{tabular}

\subsection{Mix Proportion}

The mix proportion used for the M70 high strength concrete is given in Table-3

Table-3: Mix Ratio

\begin{tabular}{|l|l|l|l|l|}
\hline $\begin{array}{l}\text { Grade } \\
\text { of } \\
\text { concrete }\end{array}$ & $\begin{array}{l}\text { Mix } \\
\text { Proportion } \\
\text { C:FA:CA }\end{array}$ & $\begin{array}{l}\text { W/b } \\
\text { Ratio }\end{array}$ & $\begin{array}{l}\text { Micro } \\
\text { Silica } \\
\text { By Wt. } \\
\text { of } \\
\text { cement }\end{array}$ & $\begin{array}{l}\text { Super } \\
\text { Plasticizer } \\
\text { By Wt. of } \\
\text { Cement }\end{array}$ \\
\hline $\mathrm{M}_{70}$ & $1: 0.87: 2.03$ & 0.25 & $5 \%$ & $3 \%$ \\
\hline
\end{tabular}

\section{SIZE EFFECT}

Size effect is a phenomenon in $\mathrm{R} \mathrm{C}$ beams associated with reduction in shear strength owing to increase in depth. The variation of diagonal cracking shear strength and ultimate shear strength with effective depth are explained below. The above two parameters are normalized with respect to $\sqrt{f_{c^{\prime}}}$ take in to account of the inevitable differences in concrete strength. 


\subsection{Effect of Increase in Depth $(d=400$ to $500 \mathrm{~mm})$} on Normalized Diagonal Cracking Shear Strength and Ultimate Shear Strength at Diagonal Cracking

Load and Failure Load for Beams with Minimum

\section{Shear Reinforcement}

The variation of diagonal cracking shear strength and ultimate shear strength with effective depth is shown in

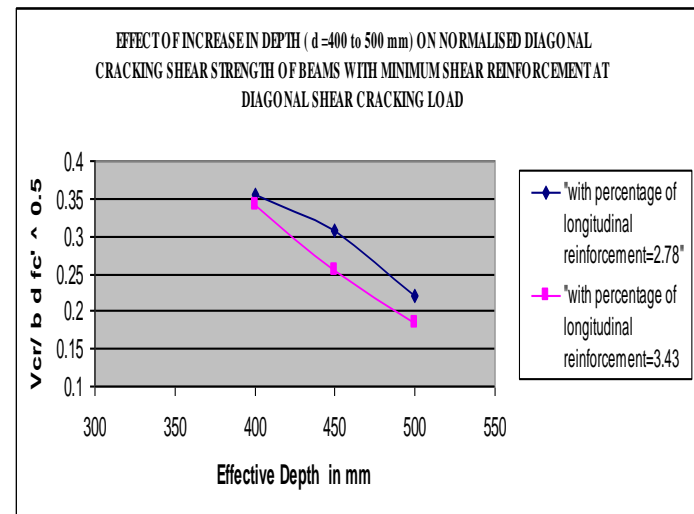

Fig -1: Influence of Normalized $\mathrm{V}_{\mathrm{cr}}$ on varying section depth

\subsection{The Influence of Amount of Longitudinal}

\section{Reinforcement on Size Effect as Effective Depth}

\section{Ranges from 400 to $500 \mathrm{~mm}$}

Beams with minimum shear reinforcement with $\rho_{\mathrm{l}}=2.78 \%$ the reduction in shear strength is $41.45 \%$ with effective depth range 400 to $500 \mathrm{~mm}$, whereas for $\rho_{\mathrm{l}}=3.43 \%$, the reduction in shear strength is $40.68 \%$. Thus in both cases there is a size effect. With increase of longitudinal reinforcement by $18.95 \%$, it does not eliminate the size effect but they only slightly mitigate it as shown in Figure 3.

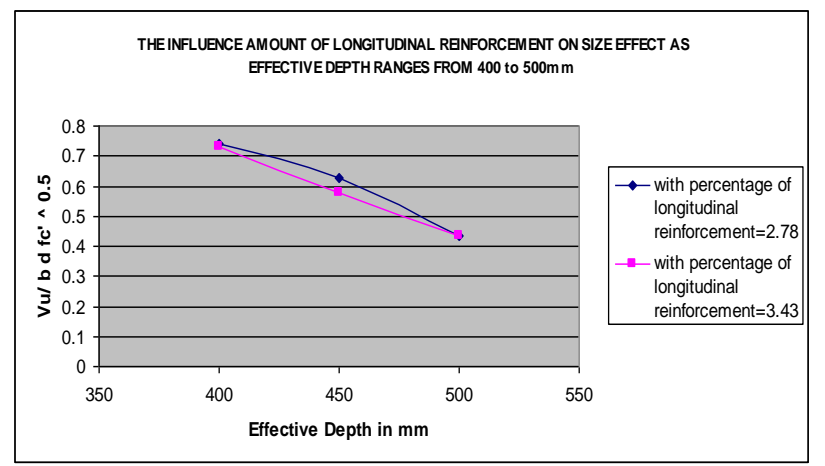

Fig -3: Influence of $\rho l$ on varying section depth

\subsection{The Influence of Amount Shear Reinforcement}

\section{(Minimum or Slightly Higher than the Minimum)}

$\mathrm{RC}$ slender beams with minimum shear reinforcement, with increase in shear reinforcement by $9.4 \%$ the ultimate shear strength reduces from $27 \%$ to $24 \%$ as shown in Figure
Figure $1 \& 2$. It has been observed as the effective depth increase from 400 to $500 \mathrm{~mm}$ for beam with minimum shear reinforcement, there is a reduction of cracking shear strength and ultimate shear strength by $45 \%$ and $35 \%$ respectively. Thus clearly indicate, there is a significant size effect in diagonal cracking shear strength and ultimate shear strength of beams with minimum shear reinforcement.

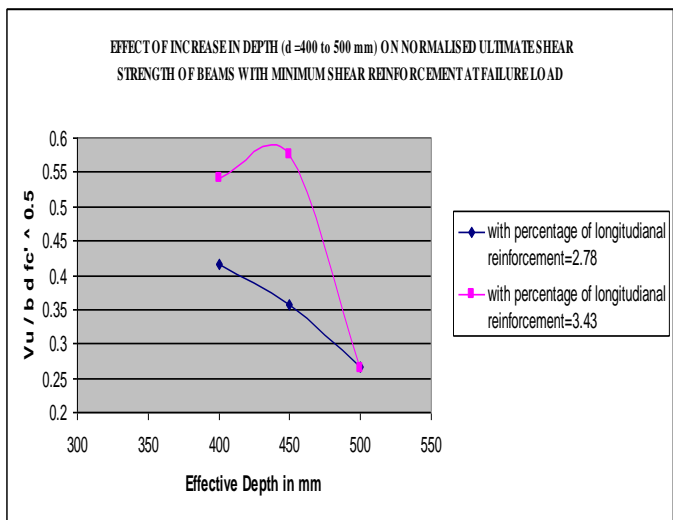

Fig-2: Influence of Normalized $\mathrm{V}_{\mathrm{u}}$ on varying section depth

4.Thus beams with shear reinforcement whether minimum or heavier than the minimum, is unable to suppress the size effect it mitigates the size effect .

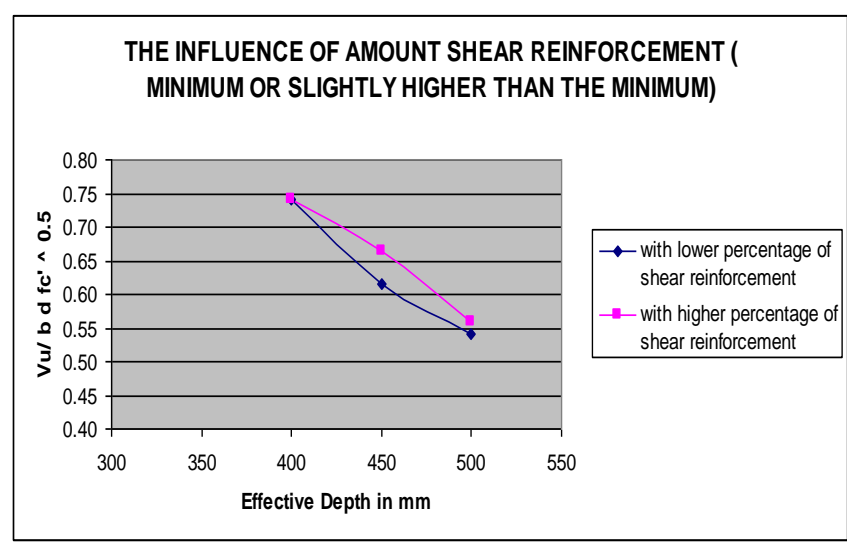

Fig-4: Influence of $\rho v$ on varying section depth

\subsection{Influence of Reserve Shear Strength Index (R) with Varying Depth}

Reserve shear strength is defined as the ratio of $\mathrm{V}_{\mathrm{u}} / \mathrm{V}_{\mathrm{cr}}$ as criteria to measure the reserve strength. It can be understood from the observation that the increase in overall depth leads to decrease in load carrying capacity after the diagonal crack this results in wider cracks and higher energy released rate at the front of cracks due to reduction of shear strength. The reduction in $\mathrm{R}$ as depth increased from 400 to $500 \mathrm{~mm}$ is from 1.85 to 1.76 . The variation of decreasing reserve shear strength is shown in Figure 5. 


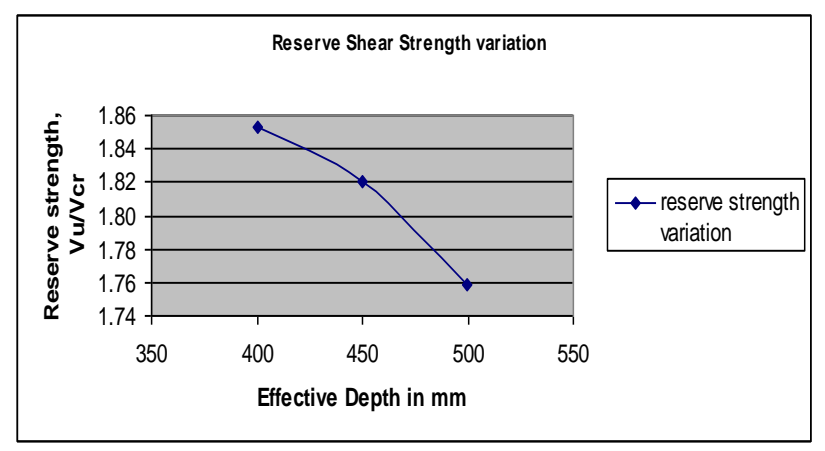

Fig-5: Influence of Reserve shear strength on varying section depth

\subsection{Comparison of Experimental Shear Strength} with Theoretical Tensile Strength as per CEB-FIP

\section{Model 1990}

The tensile strength of beams has been calculated both from load level at initiation of diagonal crack and also from cube strength according to model code 90 (CEB-FIP model code 1990). It can be seen that beams with a diagonal tension failure the ratio between the two is slightly below one. For beams with compression failure all ratios more than one. Thus confirming with the experimental result.

Table-4: Calculation of tensile strength

\begin{tabular}{|c|c|c|c|c|c|c|}
\hline Specimen & $\begin{array}{l}\text { Breadth } \\
\text { of beam }\end{array}$ & $\begin{array}{l}\text { Effective } \\
\text { Depth -d } \\
\text { in } \mathrm{mm}\end{array}$ & $\begin{array}{l}\text { Applied } \\
\text { Shear }\left(\mathrm{V}_{\mathrm{cr}}\right) \\
\text { in KN }\end{array}$ & $\begin{array}{l}\text { Actual } \\
\text { tensile } \\
\text { stress, } \\
\mathrm{f}(\mathrm{t}) \text { exp } \\
\text { in } \\
\mathrm{N} / \mathrm{mm}^{2}\end{array}$ & $\begin{array}{l}\text { Theoretical tensile } \\
\text { stress } \\
\mathrm{S}_{\mathrm{v}}(\text { the })=0.24\left(\mathrm{f}_{\mathrm{ck}}\right)^{0.66}\end{array}$ & $\begin{array}{l}\mathrm{f}(\mathrm{t}) \\
\exp / \mathrm{S}_{\mathrm{v}}(\text { the })\end{array}$ \\
\hline MNR1 & 150 & 400 & 145 & 2.42 & 3.65 & 0.66 \\
\hline MNR2 & 150 & 450 & 140 & 2.07 & 3.65 & 0.57 \\
\hline MNR3 & 150 & 500 & 110 & 1.46 & 3.65 & 0.40 \\
\hline NNR1 & 150 & 400 & 120 & 2 & 3.04 & 0.66 \\
\hline NNR2 & 150 & 450 & 100 & 1.48 & 3.04 & 0.49 \\
\hline NNR3 & 150 & 500 & 90 & 1.2 & 3.65 & 0.33 \\
\hline ONR1 & 150 & 400 & 145 & 2.42 & 3.04 & 0.80 \\
\hline ONR2 & 150 & 450 & 100 & 1.48 & 3.04 & 0.49 \\
\hline ONR3 & 150 & 500 & 80 & 1.07 & 3.04 & 0.35 \\
\hline
\end{tabular}

\subsection{Effect of Increase in Depth on Post Cracking}

\section{Behavior or Shear Strength Provided by Stirrups}

Based on ACI code the shear strength provided by stirrups can be calculated by using the equation $V_{s}=f_{y} A_{s v} d / S_{v}$ the term $f_{y} A_{s v}$ is the shear strength provided by one stirrups and $\mathrm{d} / \mathrm{S}_{\mathrm{v}}$ is the number of stirrups crossing the diagonal crack and shear crack angle is assumed to be 45 degrees for all the tested beams, the beam size, effective depth and the stirrup spacing did not influence the angle at which primary shear cracking occurred the test results indicate that the primary shear crack angle varied between 30 to 45 degrees regardless of size and stirrup spacing.

$$
\mathrm{V}_{\mathrm{s}}(\text { predicted as per ACI })=\mathrm{f}_{\mathrm{y}} \mathrm{A}_{\mathrm{sv}} \mathrm{d} / \mathrm{S}_{\mathrm{v}}
$$

$\mathrm{V}_{\mathrm{s}}$ (Actual) $=\mathrm{N}_{\mathrm{v}} \mathrm{f}_{\mathrm{y}} \mathrm{A}_{\mathrm{sv}}$ and this is equal to stirrup capacity where,

$\mathrm{N}_{\mathrm{v}}$ is the number of stirrup crossing the shear angle (full integer quantity).

Shear capacity analysis with varying effective depth for the first group specimens are shown in Table IV.

Table-5: Stirrup Capacity

\begin{tabular}{|l|l|l|l|}
\hline Specimen & $\begin{array}{l}\text { Effective } \\
\text { Depth -d in } \\
\text { mm }\end{array}$ & $\begin{array}{l}\text { Stirrup } \\
\text { capacity } \\
\mathrm{V}_{\mathrm{s}}(\mathrm{KN})\end{array}$ & $\begin{array}{l}\text { Shear } \\
\text { cracking } \\
\text { angle }\end{array}$ \\
\hline MNR1 & 400 & 123.69 & 34 \\
\hline MNR2 & 450 & 114.845 & 36 \\
\hline MNR3 & 500 & 83.43 & 45 \\
\hline
\end{tabular}

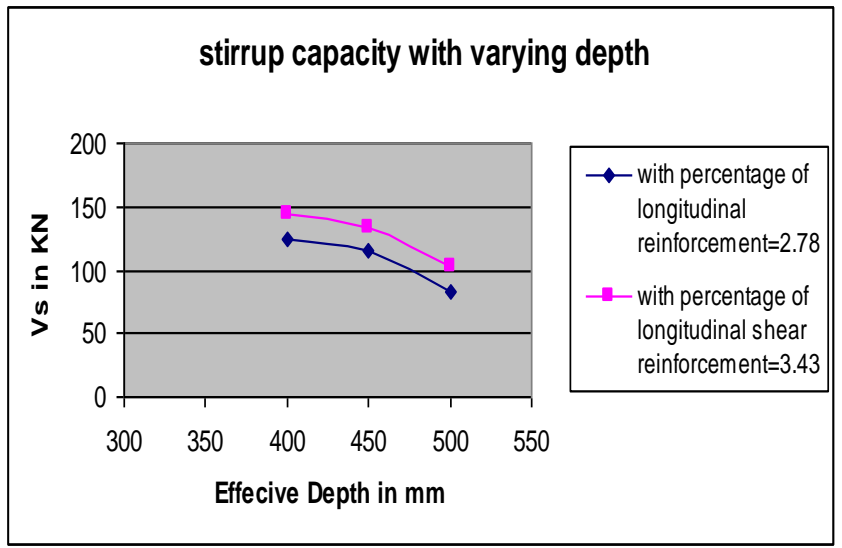

Fig-6: Influence of Stirrup capacity on varying section depth

The shear crack angle determines the number of stirrup crossing the diagonal crack. Steeper angle resulted in a decrease in number of stirrups that cross the diagonal crack. It can be observed that crack angle is affected by size effect. 
For beams MNR1 to MNR3, shear strength provided by stirrups decreases by $31 \%$ for effective depth between 400 and $500 \mathrm{~mm}$. For the beams with $\rho_{1}=2.78$ and $\rho_{1}=3.43$, the influence of stirrup capacity with varying section depth as shown in Figure 6.

\subsection{Comparison Of Test Results With Various}

\section{Shear Code Provisions And Shear Design Equations}

The experimental diagonal cracking load and failure load is compared with the theoretical one calculated as per different codes and based on this Figure 7 and Figure 8 shows the comparison of diagonal cracking load and failure load for different codes respectively.

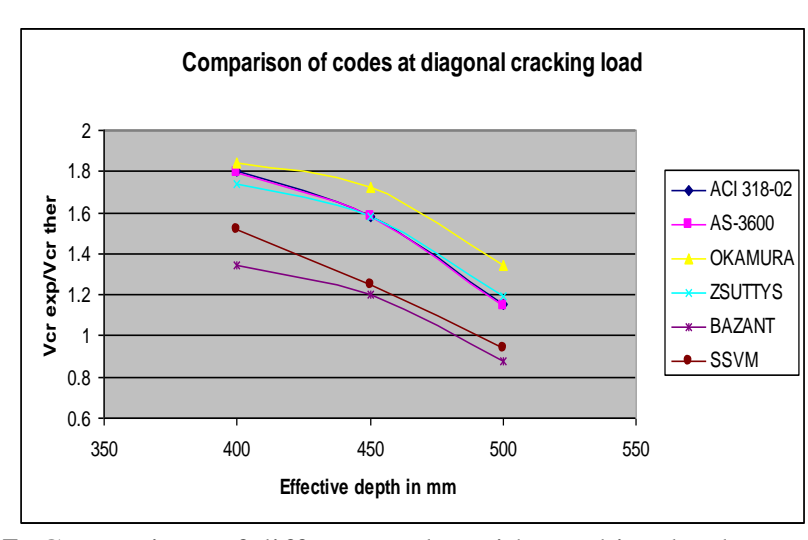

Fig-7: Comparison of different codes with cracking load

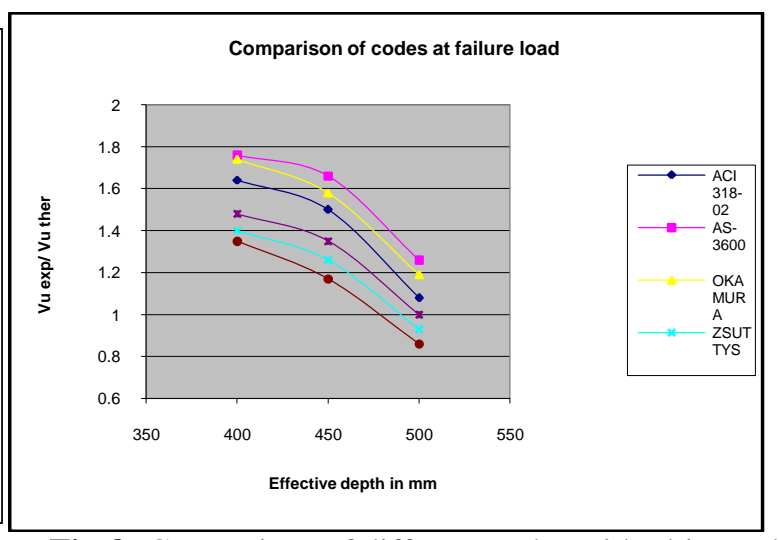

Fig-8: Comparison of different codes with ultimate load

From Figure 8, it is clear that all the different codes consider in this paper are predicting decreasing order while increasing in section depth. ACI code gives conservative predictions for slender beams it can be seen that this conservative trend decreases within increase of beam depth. The Bazant's method can predict the trend of the influence of effective depth on shear strength of high strength concrete beam, it also underestimate the ultimate strength.

\section{SUMMARY AND CONCLUSIONS}

Experimental investigation on shear behavior of slender beams with size effect is important because many of the shear design code provisions are principally empirical, vary greatly from code to code and do not provide for uniform factors of safety against failure. For these reasons, nine reinforced concrete beams with medium effective depth range between 400 to $500 \mathrm{~mm}$, longitudinal percentage ranging from 2.78 to 3.43 and minimum shear reinforcement percentage from 0.2682 to 0.37 with constant concrete strength $\mathrm{f}_{\mathrm{ck}}=70 \mathrm{MPa}$ and shear span to effective depth ratio $\left(\mathrm{a}_{\mathrm{v}} / \mathrm{d}=2.6\right)$, were tested to shear failure under two symmetric point loading. The principle findings from experimental results are summarized as follows

* For the RC slender beam tested here with minimum shear reinforcement as per ACI code, as depth increased from 400 to $500 \mathrm{~mm}$ (medium effective depth range) there was a corresponding decrease of $45 \%$ in concrete shear strength in diagonal cracking load and $20 \%$ in ultimate shear strength and that is there is a size effect. Thus there was more pronounced size effect in medium effective depth

beams $(\mathrm{d}=400$ to $500 \mathrm{~mm})$ than in small depth range beams ( $\mathrm{d}$ less than or equal to $305 \mathrm{~mm}$ ).

* However the safety factor for shear decrease with increase in depth from 400 to $500 \mathrm{~mm}$ range which exhibit an inadequate safety factor so it can be concluded that the ACI code predictions for shear strength at diagonal cracking load and failure load, should address the size effect.

* Beams designed with minimum shear reinforcement as percentage of longitudinal reinforcement increased from $2.78 \%$ to $3.43 \%$, the normalized ultimate shear strength reduces from $41.45 \%$ to $40.68 \%$. And thus in both the cases there is a size effect and with increase of percentage of longitudinal reinforcement by $18.95 \%$, it does not eliminate the size effect but only slightly mitigate it.

* RC slender beams with minimum shear reinforcement the reduction in shear strength is $27 \%$ for 400 to $500 \mathrm{~mm}$ effective depth range. With increase of shear reinforcement by $9.4 \%$, for the same effective depth range, the reduction in ultimate strength is $24 \%$. For slender beams whether minimum or heavier than the minimum is unable to suppress the size effect.

* Reserve shear strength is defined as the ratio of $\mathrm{V}_{\mathrm{u}} / \mathrm{V}_{\mathrm{cr}}$ as criteria to measure the reserve strength. As the effective depth increases the reserve shear strength reduces from 1.85 to 1.76 . Thus confirming from the experimental result.

* It can be observed that the ratio of experimental tensile strength to theoretical tensile strength predicted by CEB FIP model code 1990 is less than one which confirms the diagonal tension failure. 
This calculation clearly shows that reinforcement distributes the stresses in the web and therefore leads to cracking at later stage.

* For beams tested in study, the beam size and the stirrup spacing did not influence the angle at which primary cracking occurred. The test results indicate that primary shear crack angle vary between 30 to 45 degrees regardless of beam size and stirrup spacing.

* It was observed that beam size did not affect post cracking behavior or shear strength provided by stirrups.

* For beams tested, shear strength provided by stirrups decreases by $31 \%$ for effective depth between 400 and $500 \mathrm{~mm}$. Considering the variation in observed shear angle, closer spacing or reduced $\mathrm{d} / \mathrm{S}_{\mathrm{v}}$ with smaller diameter stirrups, which provide a better stirrup distribution may be beneficial .

\section{NOTATIONS}

$\rho \mathrm{v} \quad=$ Shear reinforcement percentage

$\rho_{1} \quad=$ Longitudinal steel percentage

$\mathrm{f}_{\mathrm{ck}}=$ Cube compressive strength of concrete

$\mathrm{f}_{\mathrm{c}}, \quad=$ Cylinder compressive strength of concrete

$\mathrm{b}_{\mathrm{w}} \quad=$ Breadth of beam in $\mathrm{mm}$

$\rho_{\mathrm{v}(\min )}=$ Minimum shear reinforcement percentage

$\mathrm{S}_{\mathrm{v}} \quad=\quad$ Spacing between Stirrups

$\mathrm{R} \quad=$ Reserve Shear Strength Index

$\mathrm{V}_{\mathrm{s}}$ (predicted as per $\mathrm{ACI}$ ) = Stirrup capacity predicted by ACI method

$\mathrm{V}_{\mathrm{s}}($ Actual $)=$ Actual stirrup capacity

$\mathrm{N}_{\mathrm{v}} \quad=\quad$ Number of stirrup crossing the shear angle

$\mathrm{V}_{\mathrm{cr}} \quad=$ Cracking Shear Strength

$\mathrm{V}_{\mathrm{u}} \quad=$ Ultimate Shear Strength

$\mathrm{A}_{\mathrm{st}} \quad=$ Area of tensile reinforcement

$\mathrm{A}_{\mathrm{sv}}=$ Area of shear reinforcement

$\mathrm{a}_{\mathrm{v}} \quad=$ Shear span

$\mathrm{d}=$ Effective depth

$\mathrm{f}_{\mathrm{y}} \quad=$ Yield strength of steel

\section{REFERENCES}

[1] ACI Committee 318, "Building Code Requirements for Structural Concrete (ACI 318 - 05) and commentary (318R - 05), “American Concrete Institute, Farmington Hills, Mich 2005.

[2] A.F Ashour ( 2000)"'Shear Capacity of Reinforced Concrete Deep Beams" Journal of Structural Engineering, pp 1045-1052.

[3] Eric J Tompos and Robert J Frosch (2002) Influence of beam size, longitudinal reinforcement, and stirrup effectiveness on concrete shear strength." ACI Structural Journal pp -567.

[4] Evan C Bentz and Sean Buckley (2005)'"Repeating a Classic Set of Experiments on Size Effect in Shear of Members without Stirrups" ACI Structural Journal ,pp 832-838.

[5] Evan C Bentz( 2005)"Empirical Modeling of Reinforced Concrete Shear Strength Size Effect for
Members without Stirrups "ACI Structural Journal , pp 232-241.

[6] Joost Walraven and Nobert Lehwalter , (1994 )"Size Effects in Short Beams Loaded in Shear ", $A C I$ Structural Journal, pp 585-593

[7] Keun Hyeok Yang, Hee- Chang Eun, Heon Soo Chung (2006) " The influence of web opening on the structural behavior of reinforced high strength concrete deep beams" Engineering Structures 28 , 1825-1834.

[8] Michael P Collins Denis Mitchell, Perry Adebar, Frank J Vecchio (1996 )"Shear Strength of High Performance Concrete Beams , A General Shear Design “, ACI Structural Journal, pp 36-45

[9] Michael P Collins, Evan C Bentz, and Edward G Sherwood,(2008)"Where is Shear Reinforcement Required? Review of research results and design procedures" ACI Structural Journal ,pp 590-599.

[10] Prodomas D Zararis and George Ch. Papadakis (2001) "Diagonal Shear Failure and Size Effect in RC Beams without Web Reinforcement" Journal of Structural Engineering, pp 733-741.

[11] Prodomos D.Zararis (2003)"Shear Strength and minimum shear reinforcement of Reinforced Concrete slender beams", ACI Structural Journal, pp 203-214.

[12] Robert J Frosch (2000)"Behavior of large Scale Reinforced Concrete Beams with minimum shear reinforcement “ACI Structural Journal, pp 814-820.

[13] Subramanian( 2003)"Shear strength of high strength concrete beams: Review of codal provisions "The Indian Concrete Journal ,pp 1090-1094

[14] Tarek K Hassan ,Hatem M Seliem ,Hazim Dwairi, Sami H Rizkalla and Paul Zia(2008)"Shear Behavior of Large Concrete beams Reinforced with High Strength Steel" ACI Structural Journal , pp 173-179.

[15] Vijayarangan(1998)" Shear Design of Reinforced Concrete Beams, Slabs and Walls ", Cement and Concrete Composites, pp 45-464.

[16] Zdenek P Bazant (1987)"Size Effect in Diagonal Shear Failure: Influence of Aggregate Size and Stirrups “, ACI Materials Journal ,pp 259-272.

[17] Zdenek P Bazant, Qiang Yu, Walter Gerstle, James Hanson, and J.Woody Ju (2007)'Justification of ACI 446 Code Provisions for Shear Design of Reinforced Concrete Beams" ACI Structural Journal ,pp 601-607

[18] Zdenne P Bazant and Mohammad T Kazemi , (1991) "Size Effect on Diagonal Shear Failure of Beams without Stirups “ ACI Structural Journal pp 268-278. 